\title{
@) $\odot \Theta \Theta$ Reflexiones sobre el Método Paulo Freire. Más allá de un metodología, una praxis política
}

\author{
Miguel Ahumada Cristi ${ }^{*}$ \\ Xus Martín García**
}

\begin{abstract}
Resumem: A veces se enuncia a Paulo Freire como un metodólogo. Tal enunciado es solo en parte acertado, pues más allá de una simple metodología, la pedagogía de Freire es una praxis política. Para mostrar esto, que aunque parezca obvio no está tan claro en el ambiente académico, en el presente texto describiremos y reflexionaremos el método dialógico del profesor pernambucano; vale decir, haremos una comprensión crítica de las bases teóricas y la puesta en práctica de su idea de educación como liberación basada en el diálogo, su fundamentación y su praxis. En síntesis, el texto constituye un retrato comprensivo del método de concientización y de los fundamentos pedagógicos, filosóficos y políticos que respaldan a Freire.
\end{abstract}

Palabras clave: Método Paulo Freire. Liberación. Praxis pedagógico-política

\section{Reflections on Paulo Freire's method. More than a methodology, a political praxis}

\begin{abstract}
Sometimes Paulo Freire is mentioned as a methodologist. Such statement is only partially correct, because more than a simple methodology, Freire's pedagogy is a political praxis. To prove it, which seems to be obvious but it's not so clear, in this article we will describe and reflect on the dialogical method of the pernambucano professor; it is worth saying, we will make a critical

\footnotetext{
* Doutor em Educação e Sociedade pela Universidade de Barcelona (UB). Professor da Universidade Federal da Integração Latino-Americana (UNILA). E-mail: miguel.cristi@unila.edu.br

** Doutora em Educação pela Universitat de Barcelon. Professora da Facudade de Pedagogia Universidade de Barcelona (UB). E-mail: xusmartin@ub.edu
} 
comprehension of the theoretical basis and the practical result of his idea of education as a liberation based on the dialog, its fundamentation and praxis. In short, the text contitutes a comprehensive portrait of the method of awareness and the pedagogical, philosophical and political foundations that support Freire.

Keywords: Paulo Freire Method. Liberation. Pedagogical praxis-politics.

\title{
Reflexões sobre o Método Paulo Freire. Para além de uma metodologia, uma práxis política
}

\begin{abstract}
Resumo: Em ocasiões, Paulo Freire é enunciado como um 'metodólogo'. Tal enunciado é só em parte acertado, pois para além de uma simples metodologia, a pedagogia de Freire é uma práxis política. Para mostrar isto, que ainda pareça obvio não está tão claro no ambiente acadêmico, no presente texto descreveremos e refletiremos o método dialógico do professor pernambucano; isto é, faremos uma compreensão crítica das bases teóricas e da prática da ideia de educação como liberação baseada no diálogo, sua fundamentação e sua práxis. Em síntese, o texto constitui um retrato compreensivo do método de conscientização e dos fundamentos pedagógicos, filosóficos e políticos que respaldam a Freire.
\end{abstract}

Palavras-chave: Método Paulo Freire. Llibertação. Práxis político-pedagógica.

\section{Presentación}

No hay duda que Paulo Freire es el pedagogo latinoamericano más conocido a nivel mundial. Freire ha sido, todavía es y probablemente seguirá siendo fuente de inspiración para docentes e investigadores de América Latina y de los demás continentes. Por cierto, considerable es la publicación de libros, artículos y tesis de grado y postgrado que se han hecho sobre la base del pensamiento de este autor. Freire publicó más de cuarenta obras, veinticinco de manera individual y muchas de estas traducidas a más de treinta lenguas. Debido a la calidad de su 
extenso trabajo pedagógico recibió veintiocho veces la distinción Doctor Honoris Causa en universidades de distintas naciones y continentes. El día 13 de abril de 2012, tras cinco años de su muerte, la República de Brasil lo reconoció como 'Patrono de la Educación Brasileña'. Por todas estas razones, Freire es uno de los educadores más influyentes de los últimos tiempos. Es, también, uno de los grandes referentes del movimiento llamado 'Educación Popular'.

Ahora bien, como profesores universitarios de una institución latinoamericanista con bastante presencia de estudiantes extranjeros de los distintos países de la región, hemos visto que la curiosidad y actividad científica por conocer a Paulo Freire y comprender su posición educativa se va poco a poco desvaneciendo. En efecto, una gran cantidad de estudiantes de los últimos niveles de diversas carreras de pedagogía poco o nada conocen de la obra de Freire. Y lo poco que conocen en gran medida refleja un discurso confuso sobre un mero método más de los tantos que existen en el campo educacional. Amigos profesores de pedagogía de distintas universidades de Brasil, y también del extranjero, nos han comentado un panorama bastante similar. Justamente este vacío y desorientación es lo que nos anima a describir de manera ordenada y con suficiente reflexión los fundamentos de la propuesta pedagógica de Freire. Trátase de un texto que, además de científico, por extensión pretende motivar la lectura de tan distinguido profesor de nuestra América Latina.

\section{Sobre Paulo Freire}

Paulo Freire nació en el barrio de Casa Amarela, Recife, en 1921. $\mathrm{Su}$ familia estaba constituida por padre, madre y cuatro hermanos. Su primera infancia no fue la de un niño pobre, pero tampoco de un ser humano al que le sobraba, pues su madre ejercía labores de costurera y bordadora, mientras que su padre era oficial de la Policía Federal. De acuerdo a Freire (1980), de sus padres recibió una educación basada en 
el amor, el respeto y la confianza. Nuestro autor recuerda con bastante cariño las enseñanzas de sus padres, todas éstas basadas en el diálogo. En efecto, Freire llega a señalar que de ellos aprendió 'qué es el diálogo', su relevancia y su práctica amorosa. La voz y las manos de sus padres nunca fueron sinónimo de agresividad; por el contrario, equivalen al cariño y al incentivo para aprender a pensar, actuar y tomar decisiones por voluntad propia (FREIRE, 1980). Podemos decir que sus padres buscaban la formación de un sujeto autónomo cuyo autodespliegue en el mundo dependiera, más que nada, de sí mismo. Un retrato de esto es el siguiente: el padre de Freire era agnóstico (algo muy poco común en la sociedad brasileña de comienzos del s. XX), mientras que su madre era católica practicante. Freire relata que nunca fue forzado por ninguno de los dos a escoger una posición en cuanto a fe, pues él mismo decidió ser cristiano, y su padre de modo alguno se opuso. Nos apunta el propio Freire (1980, p. 13) sobre su padre: "recuerdo todavía hoy con qué cariño me escuchó cuando le dije que quería hacer mi primera comunión". En concreto, sus progenitores lo educaron con el objetivo de que por sí mismo transformara sus intereses en objetos de conocimiento y comprensión. Instancia que con los años sería de suyo relevante en su pedagogía y filosofía educacional.

Si queremos entrar de manera algo más directa a la propuesta político-pedagógica de Freire, debemos necesariamente detenernos en este acontecimiento: Freire fue un niño alfabetizado por sus padres, y de una manera muy poco convencional. El pernambucano relata que le enseñaron a leer y a escribir en una pequeña huerta al fondo de su casa, bajo la sombra de un árbol de mangos. Cuando se sentaban a la sombra de aquél, las ramas secas que caían al suelo servían como lápiz para escribir en la tierra ${ }^{1}$. Y no solo eso, nos dice Freire que "ellos me alfabetizaron partiendo de mis palabras, palabras de mi infancia,

\footnotetext{
${ }^{1}$ Esta experiencia dio origen a la obra À sombra desta mangueira. São Paulo: Olhos da Água, 1995.
} 
palabras de mi práctica como niño, de mi experiencia, y no las palabras de ellos" (FREIRE \& GUIMARÃES, 1982, p. 14). Las experiencias educativas con sus padres, como veremos más adelante, se tornarían clave en la construcción y fundamentación de su método, ¿por qué? muy simple: porque la alfabetización fue hecha a partir de las propias palabras de Freire, vocablos que retrataban intereses y experiencias existenciales suyas, no dadas.

En definitiva, los recuerdos de infancia de este autor son las de un niño alegre, aunque no falto de problemas. Con su familia aprendió a vivir en un ambiente de libertad, diálogo y creatividad; sin embargo, cuando contaba con trece años sufrió la dolorosa pérdida de su padre, lo que no solo traería problemas en el ámbito afectivo, también en el económico. Su madre, mujer decidida, fuerte y luchadora, tuvo que mantener con muchísimo esfuerzo a la familia. Freire describe que producto de la situación en ocasiones pasó hambre, pero un hambre que él se tomó no con sufrimiento, sino como una experiencia útil de vida (REYES, 1995, p. 6). Sentir 'el dolor del hambre' le permitió comprender uno de los tantos males que aquejaba, en ese entonces, a una gran parte de la sociedad: la miseria de los oprimidos.

Gracias a los esfuerzos de su valiente madre, quien luchó codo a codo por la educación de sus hijos, Freire pudo terminar la secundaria con una beca de estudios. Más tarde, a los veintidós, ingresó a estudiar abogacía en la Facultad de Derecho de Recife. Un año después se casó con Elza de Oliveira, con quien tuvo cinco hijos. Y es precisamente este acontecimiento, el matrimonio, lo que dio fuerza a la idea del Paulo Freire que nos hacemos: el abogado que se hizo, en la práctica, uno de los más conspicuos y celebrados educadores de América Latina y el mundo. Veamos:

Elza de Oliveira era profesora de primaria y, como toda buena profesora, estudiaba y preparaba parte de sus clases en el hogar. Freire, siempre curioso, no tardó en comenzar a 'robar' los libros de su esposa para leerlos. Señala que mucho más que estudiar derecho estudiaba los 
textos de educación de ella, obras que de alguna manera complementaba con lecturas de Filosofía y Sociología. Como consecuencia, mientras se formaba como abogado, se animó a ejercer labores de docencia como profesor de portugués. Estos hechos hacían dudar a Freire en el sentido de si realmente deseaba ser abogado en vez de educador. Sólo en su último año de facultad tomó la decisión, en un caso interesante de rescatar: en uno de sus primeros trabajos de abogacía tuvo que cobrar una deuda a un dentista. El odontólogo había pedido un préstamo para montar su propio consultorio. No le fue bien y por lo tanto no tenía cómo pagar lo que debía; como consecuencia, le serían embargados sus bienes. Señala Freire que tras comprender la situación del dentista, luego de escucharlo, desistió de efectuar la orden de embargo. Y ahí mismo terminó su carrera como abogado, sin siquiera haberla iniciado (FREIRE, 2007, p. 15). No obstante, sí egresó de la facultad.

En 1947 fue invitado a colaborar en el SESI (Servicio Social de la Industria) y empezó a aplicar por primera vez su método de alfabetización de adultos. Rápidamente fue nombrado Director y luego ascendido a Superintendente. En este último cargo procuró establecer un diálogo entre las familias y los alumnos, con el objeto de abarcar una educación más integradora. No fue un Superintendente de escritorio, pues mantuvo constantes encuentros con las familias y los estudiantes con el objeto de mejorar su filosofía educativa y sus prácticas pedagógicas. Comenta: "así fue como me fui haciendo, en la práctica, un educador. Y fui aprendiendo, desde aquella época, a ejercer una práctica de la no me alejé hasta hoy: la de pensar la práctica" (FREIRE \& BETTO, F., 1986, p. 9.).

En 1952 obtuvo el cargo de Profesor Interino de Historia y Filosofía de la Educación de la Escuela de Bellas Artes, actual Universidad de Recife. En 1959, defendió su tesis 'Educação e atualidade brasileira', que le valió el título de Doctor en Filosofía e Historia de la Educación. Este posgrado le permitió actuar como 
Docente Adjunto de la Facultad de Filosofía, Ciencias y Letras de la Universidad de Recife. Como académico, participó en la fundación del Movimiento de Cultura Popular (MCP). Según Franzi (2007, p. 58) el objetivo de este movimiento era esencialmente político, pues apuntaba a promover la participación de las masas populares en la sociedad brasileña, i. e., en los asuntos de Estado.

Durante el Gobierno de João Goulart (1962-1964), Freire fue organizador y participante activo de un vasto programa y método de alfabetización que alcanzó varios Estados de Brasil y un número altísimo de escuelas para jóvenes y adultos. Su método se fue extendiendo por todo el territorio brasileño, y poco a poco comenzaba a alcanzar el plano internacional. Este avance se mantendría hasta el Golpe Militar de 1964, que derrocó por la fuerza al Gobierno de Goulart. El hecho marcó el fin de la expansión del método de Freire. En efecto, en la Dictadura se 'extirpa' de las escuelas el Método Paulo Freire para sustituirlo por el método MOBRAL (sigla del Movimiento Brasileiro de Alfabetización, decreto de ley n 5.379 de 1967), cuya metodología esencialmente mecánica y funcional, y con profesores escasamente preparados, terminó en un profundo fracaso. Sobre esto, nos enseña Sauner (2002, p. 59) que

Una de las causas del fracaso del MOBRAL en su trabajo de alfabetización del joven y del adulto brasileños está relacionada a los recursos humanos: la no preparación de los monitores a quienes se les entregaba la tarea de alfabetizar. Se trataba de personas no capacitadas para el trabajo en educación, que recibían un 'cursito' de entrenamiento de cómo aplicar el material didáctico entregado por el MOBRAL y enseñaban solo la mecánica escrita de la lectura, por lo tanto, no alfabetizaban.

Establecida la Dictadura, Freire fue encarcelado por poco más de setenta días ${ }^{2}$. Al salir de la cárcel, se refugió en la Embajada de Bolivia

\footnotetext{
${ }^{2}$ Estuvo durante todo ese tiempo encerrado en una celda de no más 70 centímetros de ancho por 1,80 metros de largo.
} 
y un mes más tarde viajó a La Paz. Infelizmente, tras apenas dos semanas en la capital boliviana, hubo también un Golpe en dicho país, lo que obligó a Freire a viajar a Chile, país que en ese entonces era uno de los pocos estados que gozaba de una democracia vigente. En Chile, fue contratado por la Corporación de Reforma Agraria para colaborar en las políticas y prácticas de alfabetización de trabajadores rurales. De esta labor nació su obra ¿Extensión o Comunicación? (1968), creada para el Programa de Educación de Trabajadores Agrarios de Chile. Dicha obra plantea, al igual que sus anteriores libros, la idea de una educación dialógica que no se sobreponga violentamente a los saberes populares.

Entre finales de 1968 y 1970, tiempo en que publica su obra más conocida, la Pedagogía del Oprimido $^{3}$, trabajó en Harvard como profesor invitado ${ }^{4}$. Luego de esta experiencia, ejerció labores en Ginebra como consejero educativo. Realizó varios viajes a África y Asia donde ministró seminarios sobre métodos pedagógicos y sobre los problemas sociales de América Latina y el Caribe. Luego de la independencia de Mozambique, Cabo Verde y Angola, fue llamado a colaborar en la planificación educacional de estos estados (FREIRE, 1977, 2003).

\footnotetext{
${ }^{3}$ Obra mayoritariamente escrita en Chile, cuyo manuscrito original es en portugués, fue publicada primero en inglés, español, francés, italiano y alemán. Vino a ser recién editada en Brasil en 1975. La Pedagogía del Oprimido nace tras el contacto que tuvo Freire con el socialismo cristiano de Chile, con el contacto que mantuvo con sus compatriotas también exiliados y con los movimientos populares y marxistas del país cordillerano. En efecto, es en Chile donde Freire realiza sus más profundas lecturas de Marx y de los marxistas occidentales, africanos y orientales más en boga en dicha época. Puede decirse que el concepto clave de la Pedagogía del Oprimido, a diferencia de otras obras, es 'revolución'.

${ }^{4} \mathrm{Su}$ obra, Educação como prática da libertade, publicada en Rio de Janeiro en 1967, se hizo bastante conocida en el ambiente académico de EEUU. El texto colaboró significativamente en el llamado que le hizo la Universidad de Harvard. Por cierto, inmerso en los EEUU, observó que los problemas de opresión, marginalización, violencia, racismo, no se reducían apenas a América Latina. EE.UU en los años 60 vivía en un clima de tensión, represión y de luchas reivindicacioncitas.
} 
Al volver a Brasil, en 1980, fue nombrado catedrático de la Pontificia Universidad Católica de São Paulo (PUC-SP) y posteriormente, casi por una década, docente de la Universidad de Campinas (FREIRE, A., 2006).

En 1988, el Partido de los Trabajadores (PT), del cual Freire fue colaborador en la fundación, ganó las elecciones municipales de la ciudad de São Paulo. Tras la victoria, Freire asume la Dirección de la Secretaria de Educación Municipal. En ese momento se destaca la propuesta de creación del Movimiento de Alfabetización (MOVA), el que se expandió más allá de las fronteras de la ciudad, siendo adoptado por una gran cantidad de estados de Brasil. Terminado el periodo del gobierno del PT en la capital paulista, Freire retomó sus labores en la PUC-SP y dictó constantemente seminarios en la Universidad de São Paulo. Hasta su muerte, apoyado de sus convicciones de corte socialcristiano, forjó sus ideas pedagógicas como un pensamiento político. $\mathrm{Su}$ visión educativa, siempre humanista, se centró en la integración de los sujetos, en especial los oprimidos, al mundo. Freire murió en 1997, pero su obra no. El tan distinguido como querido profesor pernambucano nos sigue hablando desde su legado pedagógico. Veamos, entonces, qué nos dice:

\section{Su pensamiento político-pedagógico}

Hacer una síntesis, cuando se trata de una obra tan rica como vasta, es por lo menos injusto. No obstante, aunque no nos sea de agrado, y sí sea por razones de espacio, sinterizaremos las tesis más importantes de Freire. Nos alivia que luego estas ideas las retomaremos y profundizaremos algo más cuando expongamos su método dialéctico.

En ocasiones, algunos teóricos enuncian a Paulo Freire como un metodólogo. Esta visión es sólo en parte acertada, puesto que no explica el fondo de la propuesta de Freire, que va más allá de un método pedagógico. Freire es autor de una pedagogía nueva en su 
tiempo, cuyo fin es la liberación de quienes son oprimidos por las élites oligárquicas nacionales y el imperialismo. Se vuelve violentamente contra los modelos educativos tradicionales, que según él no hacen más que perpetuar la opresión tanto desde una perspectiva estrictamente pedagógica como política. Con el objetivo de cambiar estos modelos, Freire propone no sólo el cambio de los contenidos, sino también en la técnica pedagógica a partir de tres premisas ${ }^{5}$ :

Premisa 1. La educación no será mecánica, impositiva o autoritaria. En términos de Freire, la educación no será "bancaria", puesto que los saberes no serán depositados en la conciencia del educando cual depósito se hace en un banco; por el contrario, la educación deberá ser un instrumento para conocer el mundo y a sí mismo de modo reflexivo y crítico que lleve a la toma de decisiones, a la acción y a la corrección del error. La educación será un espacio de problematización.

Premisa 2. La esencia del método, aunque se puede encontrar en la mayéutica socrática (por su carácter dialógico), es revolucionaria en estricto rigor: la implicancia política es muy obvia, puesto que Freire rechaza el vanguardismo político-partidista que, aunque no lo haya sido en las intenciones, ha probado ser eminentemente paternalista y manipulador. Para una política educacional de Estado, el método de Freire tiene la novedad de proponer la educación 'desde las bases', es decir, desde el pueblo. De ahí que Freire sea considerado, junto a Aníbal Ponce, uno de los exponentes más nombrados de la Educación Popular de América Latina.

\footnotetext{
${ }^{5}$ Confrontar: Pedagogía del Oprimido. México DF: Siglo XXI, 2008; Pedagogia da autonomia. Saberes necessários à prática educativa. São Paulo: Paz e Terra, 2005a.; Pedagogia da Tolerância. Petrópolis: Vozes, 2005b; A África ensinando a gente. São Paulo: Paz e Terra, 2003; Extensão ou comunicação. São Paulo: Paz e Terra, 2002; La importancia de leer y el proceso de liberación. México DF: Siglo XXI, 2001a; Educação como prática de liberdade. Rio de Janeiro: Paz e Terra, 1989; Educação e mudança. São Paulo: Paz e Terra, 1986; Conscientização: teoria e prática da libertação. São Paulo: Cortez \& Moraes, 1980.
} 
Premisa 3. El centro educativo de Freire no es la pedagogía tradicional (bancaria), con el binomio maestro-alumno, estructura que se basa en la 'transmisión de la verdad' y no en su descubrimiento. Esta estructura separa a los que aprenden entre sí, fomenta el individualismo y la competencia, conduce al servilismo a la autoridad que representa el maestro, autoridad que institucionalizada la opresión (a nivel macro, el Estado; a nivel micro, las escuelas) contribuye a la petrificación pasiva de los valores impuestos y vigentes, y no a su comprensión activa y a su perfeccionamiento. Su metodología se aplica, pues, en lo que Freire llama 'círculos de cultura', en que el maestro es un coordinador/animador de diálogos y debates, y donde entre todos los participantes descubren los saberes, los conocimientos, la realidad, la 'verdad'. El círculo de cultura es, entonces, una escuela de sociabilidad, de diálogo, de reflexión en común, de libertad de palabra, de compromiso con la realidad, de investigación, de creatividad y de libertad para la liberación.

Estas premisas conducen a pensar que la educación en Freire es una práctica real, una vivencia, una pedagogía para la libertad. Y esta liberación es, grosso modo, un intento por humanizar, acción que consiste, nada más ni nada menos, en la liberación de la conciencia. A través del diálogo concientizante, cuyo objetivo es transformar la conciencia que no capta su estado de oprimido en una conciencia reflexiva y crítica, i. e., que conoce su estado y la realidad; la problematiza, la descubre y apela a la autonomía ${ }^{6}$.

\footnotetext{
${ }^{6}$ Freire define la conciencia de mujeres y hombres hacia su mundo. Para él hay tres tipos de conciencia: a) la conciencia intransitiva: no tiene relación con el tiempo, confunde los retos, no capta la causalidad de las cosas y se vuelve entonces hacia la magia (en este caso vista la magia como misterios del mundo por la adivinación), no comprometiéndose existencialmente con el mundo. b) la conciencia transitivamente ingenua: se caracteriza por ser abierta, capta la realidad, aunque no necesariamente la interpreta de manera correcta. Tiene la tendencia de volver a una feliz intransitividad. Es emocional y más polémica que dialogante. Si no se dirige a una conciencia transitivamente crítica se puede transformar en una conciencia fanatizadora. c) la conciencia transitiva crítica: es profunda en la interpretación de los "restos" y busca las causas de los hechos o fenómenos, por ejemplo, en la ciencia (no solo en "el sentido común") o en la filosofía y teología (no en la
} 
Para Freire, la liberación del oprimido, esto es, el fin de la opresión, traerá la humanización no sólo del oprimido, sino también para el opresor, lo que constituye, finalmente, su último más importante objetivo. A continuación esbozamos el pensamiento políticopedagógico de Freire ${ }^{7}$ :

Como dijimos, Freire señala que el primer paso del proceso liberador es la liberación de la conciencia, i. e., su desalienación. El proceso en cuestión se inicia situando la conciencia en situaciones desafiantes que se dan en contextos existenciales, mediante la puesta en vigor de los más elevados valores que pueda disponer el grupo dialogante. En otras palabras, el diálogo buscará 'el ser' en su 'aquí' y en su 'ahora'. Para Freire, la palabra es nada si no lleva a la acción; por lo tanto, al enseñar a leer se enseña también a conocer bien el sentido de la palabra. El sentido de la palabra es el sentido de la realidad que contiene esa palabra, según cómo la interpreta el que aprende. Siendo así, el diálogo y/o debate centra su acción más en el cuestionar que en el afirmar. De esta manera, al igual que en la mayéutica socrática ${ }^{8}$, el

magia). Procura verificar sus descubrimientos y está abierta a la crítica y a la revisión. Desea desligarse de conceptos prefabricados (que se ven como perpetuos) y niega la transferencia de la responsabilidad, porque según Freire la responsabilidad se genera en climas de libertad, y no en un acto autoritario de elementos preconcebidos. Estas características son las que hacen una conciencia transformadora y problematizadora. Resta destacar que en otras instancias a los estados de la conciencia Freire les llamó de otra forma, aunque focalizadas a otros contextos: conciencia primaria, mágica y crítica.

7 Confrontar: Pedagogía del Oprimido, op. cit.; Pedagogia da autonomia. Saberes necessários à prática educativa. São Paulo: Paz e Terra, 2005.; La importancia de leer y el proceso de liberación. México DF: Siglo XXI, 2001a; Política y Educación. México D.F: Siglo XXI, 2001b. Educacão como prática de liberdade. Rio de Janeiro: Paz e Terra, 1989; Freire, P.; Macedo, D. Alfabetização, leitura do mundo leitura da palavra. São Paulo: Paz e Terra, 2006.

${ }^{8}$ El 'método socrático' tiene dos momentos: la ironía y la mayéutica. En la cultura griega por ironía se entendían varias ideas. Primero, no era un sarcasmo, como hoy en día se puede entender, menos una forma de arribismo; ironía para los griegos era la capacidad de dejar que el otro se expresase libremente aun cuando no se concordara con él. No es posible observar que Sócrates, en sus diálogos, diga a su pares dialogantes que estaban equivocados (ni él manifestar tener la razón de las cosas), simplemente los animaba a continuar la conversación utilizando estas palabras: "muy bien, querido amigo, pero...". Luego de ese 'pero' formulaba una pregunta; luego de la respuesta, otro interrogante. En estricto rigor, lo 
diálogo será más productivo, en cuanto así el sujeto dialogante puede conseguir la real comprensión de las cosas y estados de cosas que 'habitan' en el mundo. Ese diálogo, que podemos calificar de fecundo, es aquel que permite llevar a cabo el proceso de liberación, puesto que la 'verdad' ha sido liberada por el grupo dialogante.

Freire pensaba que tras todo acto educativo hay una filosofía de la educación. Por ello es que la liberación se da en Freire como un proceso que debe tener origen, en primer lugar, en la forma de educar; es decir, cómo educar(nos) a(con) los oprimidos para que el proceso de liberación se construya de manera colectiva y 'natural'. Puesto que la liberación de los oprimidos significa el fin de la opresión, con ella también se ha de liberar al opresor de su propia alienación, la de oprimir. Es por esta razón que para Freire el concepto liberación se relaciona con el de la humanización de todos los seres humanos, de los oprimidos y de los opresores. La liberación de los oprimidos es, entonces, una transformación del mundo que conlleva la superación de todo tipo de alienación.

En estados cuyos gobiernos oprimen o favorecen la opresión, se está viviendo, según Freire, la 'falta de libertad real' que es uno de los efectos de la explotación capitalista. Al oprimido sólo le es posible obtener la libertad a través de la acción práctica, lo que equivale decir que la liberación en Freire es, como en todo marxista, una praxis que surge -además de la toma de conciencia del oprimido- de ciertas condiciones históricas existentes, v. gr., que el oprimido pueda entenderse como oprimido tomando como referencia su realidad

que solía hacer Sócrates no era menoscabar al otro, sino ayudarlo y 'ayudarse', mediante preguntas certeras y precisas, a construir o liberar una verdad más objetiva. La ironía en Sócrates, como lo apunta Brun (1984, pp. 115-117), era una 'ironía interrogante' y no un 'malestar para la consciencia', como algunos creen. La mayéutica, por otra parte, es la finalización del diálogo, i. e., cuando el otro es capaz de dar a luz un nuevo sentido respecto al tema en cuestión. En el fondo, apoyado de su 'ironía interrogativa', Sócrates construía conocimiento a partir de los saberes que estaban instalados embrionariamente en el otro: le ayudaba a parirlos (mayéu), i. e., a tener una mejor conciencia de ellos. Siendo así, todos conseguían aprender ideas nuevas y más objetivas, incluyendo, obviamente, a Sócrates. 
histórica concreta (FREIRE, 2008; FROMM, 1994). Para Freire, la libertad representa una posibilidad que requiere de una realización práctica, y esta 'libertad práctica', a su vez, sólo se puede cristalizar en la 'experiencia práctica' (que Freire también llamaría de 'saber de experiencia hecho'). Para quienes no conocen nada de Freire, este punto es importantísimo puesto que es de concluir que la libertad para Freire, si se ha de definir desde la filosofía, deberá serlo desde la perspectiva filosófica marxista de base heracliteana: más que 'libertad', ha de hablarse de liberación. Nos dice el propio Freire:

[E]n una visión dinámica de la revolución, ésta no tiene un antes y un después absolutos, cuto punto de división está por el acceso al poder. Generándose en condiciones objetivas, lo que busca es la superación de la situación opresora, juntamente con la instauración de una sociedad de hombres en proceso de permanente liberación (FREIRE, 2008, p. 166)

En suma, la educación en Freire debe ser parte de un proceso de liberación que permitirá realizar una revolución política y social. Liberar a los hombres y mujeres, entonces, es un acto de liberación del yugo de la inconsciencia y de la opresión histórica. De esta manera, las masas oprimidas y todos los seres humanos en general realizan su liberación a través del conocimiento. De manera que la educación en Freire, como materia filosófica y praxis, es un proceso real sin el cual no habrá liberación (AHUMADA, 2010).

Pues bien, podemos observar que Paulo Freire quiso instalar una forma de ejercer pedagogía que favorezca la construcción de sociedades más justas, pluralistas y empáticas. Una educación que permita liberar a las víctimas de la opresión, a quienes les han robado el derecho de cultivar un proyecto autónomo de vida; es decir, a aquellos que aún no poseen autonomía ni se sienten relevantes en las responsabilidades que les impele el mundo, que es también su mundo. Esta nueva pedagogía desafía a romper el silencio, silencio que torna a 
los seres humanos en objetos, y construir desde la educación un mundo de seres libres; es decir, sujetos (FREIRE, 2007, 2008).

En fin, las ideas pedagógicas de Freire necesitaban irse constituyendo en la forma de un plan de acción; esto es, a partir de una metodología que bien favoreciera la concretización de sus objetivos. Es en este punto de nuestro diálogo en donde podemos entrar directamente en los profundos detalles del método de Freire. Continuamos...

\section{El Método de Paulo Freire}

Importante es comenzar señalando que más que construir un método -en el sentido de una más de las tantas propuestas didácticometodológicas que existen- Freire lo que hace es juntar y cohesionar, en teoría y práctica, sus experiencias educativas, describirlas, pensarlas y re-pensarlas, fundamentarlas y re-fundamentarlas, complementarlas y perfeccionarlas a lo largo de toda su vida. Nuestro autor no acostumbraba llamar a su ejercicio pedagógico simplemente de 'método' (aun cuando en ocasiones haya utilizado tal concepto), sino más bien de praxis liberadora, pedagogía de la liberación, educación problematizadora, pedagogía de la pregunta, educación revolucionaria. El caso es que en el desarrollo de la construcción teórica y práctica de su propuesta político-pedagógica a estas experiencias a se les vino a llamar de Método Paulo Freire. Indiferente de estas cuestiones, de lo que no se podría siquiera dudar es que Freire construye un método dialéctico combinando la teoría con la práctica (especialmente sus experiencias de alfabetización de adultos) que fue cristalizándose a partir de la reflexión sobre la práctica.

Pues bien, huelga decir que el Método Paulo Freire, en adelante, MPF, es una propuesta de liberación; ergo, no se puede entender como una mera técnica o método. Es la materialización y ejercicio de una concepción del mundo, del ser humano, de la libertad y de la relevancia del diálogo. En su fundamentación es posible percibir una 
inmensa confianza en los hombres y mujeres, en que todos somos capaces de aprender constantemente en nuestras relaciones establecidas los unos con los otros (FREIRE, 2006). En el enunciado más conocido del pernambucano esto se concretiza en la práctica: "nadie educa a nadie, así que nadie se educa a sí mismo, los hombres se educan en comunión, y el mundo es el mediador" (FREIRE, 2008, p. 92). Trátase, en el fondo, de un intento por abandonar paradigmas de educación jerárquica.

Mencionamos que nuestro autor comenzó a aplicar seriamente el método en la década del sesenta, en el llamado Movimiento de Cultura Popular (MCP), una época marcada por la participación popular en los movimientos sociales ${ }^{9}$. En Recife, Freire vivió una pequeña experiencia con la práctica del método: tuvo cinco alfabetizandos, quienes consiguieron aprender a leer y a escribir en poco tiempo. Esto animó a Freire a continuar con sus objetivos (BRANDÃO, 1991).

Fueron las ciudades de Angicos y Mossoró, en Rio Grande do Norte, y en João Pessoa, en Paraíba, en donde aplicó por primera vez la alfabetización por medio de los 'círculos de cultura'. Y puede decirse que es precisamente en este momento donde Freire comienza una pedagogía liberadora. Ya no se trataba apenas de alfabetizar, sino de concientizar al alumno respecto de su posición en el mundo. Esta experiencia obtuvo gran fama, puesto que los sujetos fueron alfabetizados en entre un mes y medio y dos meses. Ciudades como Rio de Janeiro, São Paulo y Brasilia solicitaron los servicios de Freire. Finalmente, nos hacemos el interrogante clave: en concreto, ¿en qué consiste su tan célebre método?

Podemos decir que el MPF comprende dos grandes momentos: el levantamiento del 'universo vocabular' y la aplicación de los 'círculos de cultura'. El universo vocabular corresponde a un cosmos de

\footnotetext{
${ }^{9}$ Sobre ese momento histórico y político, Carlos Rodrigues Brandão (1991) afirma que fue la única vez que efectivamente la educación en Brasil ha tenido el coraje de ser creativa y soñar que podría servir para liberar al ser humano y no domesticarlo.
} 
palabras, ideas o temas de uso frecuente y de gran valor en la cultura de los involucrados, i. e., vocablos asociados a importantes experiencias existenciales. Los círculos de cultura son sesiones dialógicas basadas en la problematización de una palabra o idea que pertenece al universo vocabular. Esta dinámica se lleva a cabo a partir un método asociado a la mayéutica socrática, es decir, basado en la pregunta más que en la afirmación, para finalmente llegar a una comprensión más completa del tema/concepto. Para Freire la pregunta es una forma de indagar en la curiosidad, de descubrir cosas; la pregunta es una forma de profundizar lo que no se sabe, es la manera de descubrir mediante la curiosidad las cosas que aún no se saben o que no se comprenden bien. El profesor, para Freire, debe estar abierto a todo tipo de pregunta, sin considerar ninguna de ellas como torpe o fuera de contexto, puesto que eso puede 'matar' la curiosidad del alumno. Por el contrario, debe ayudarlo a "rehacer la pregunta, con lo que el educando aprende, haciendo, a preguntar mejor” (FREIRE \& FAÚNDEZ, 2002, p. 48).

En fin, las palabras reciben el nombre de 'generadoras' porque al ser problematizadas promueven desafíos a la comprensión crítica, generan curiosidad por saber más y mejor ${ }^{10}$. También se denominan generadoras porque su discusión hace posible 'parir', 'dar a luz', saberes antes desconocidos (mayéu). Por añadidura, la discusión de las palabras generadoras favorece el aparecimiento y la edificación de virtudes, valores y actitudes políticas y morales como el respeto por la opinión del otro, la participación, la empatía, la pluralidad y, por sobre todo, el amor por el conocimiento, i. e., el ser más. Último valor capaz de generar conciencia real del mundo y en consecuencia actuar 'humanamente' en él.

\footnotetext{
${ }^{10} \mathrm{Ha}$ de entenderse la 'comprensión crítica' bastante similar a la concientización, esto es, como el proceso mediante el cual la relación conciencia-mundo se sitúa, comprensivamente, en un contexto histórico. Capta la realidad y construye los elementos para su transformación.
} 
A continuación, explicaremos los detalles de las etapas del método de Freire:

a) Etapa 1: la colecta del universo vocabular y la selección de las palabras generadoras

En general, antes de Freire los métodos de alfabetización solían transmitir saberes predeterminados, conocimientos listos para ser digeridos. Muy por el contrario, en el MPF los saberes deben ser construidos junto a los alfabetizandos, partiendo de sus experiencias, de sus conocimientos, de sus creencias, de sus comprensiones sobre el mundo, de sus formas de establecer relaciones con la naturaleza. En este proceso, de acuerdo a Freire, el diálogo es un elemento fundamental.

Freire pensaba que, en la educación para adultos, un material ya definido tiende a infantilizar a los educandos y a colocar al profesor como aquel 'magister dixit' que todo lo sabe. En este escenario, el profesor transmite conocimientos de manera 'bancaria' y a partir de situaciones que en nada se aproximan a las vivencias de los y las estudiantes. Desde otra perspectiva, en la visión bancaria de la educación

el saber, el conocimiento, es una donación de aquellos que se juzgan sabios a los que juzgan ignorantes. Donación que se basa en una de las manifestaciones instrumentales de la ideología de la opresión: la absolutización de la ignorancia, que constituye lo que llamamos alienación de la ignorancia, según la cual ésta se encuentra siempre en el otro (FREIRE, 2008, p. 73)

El docente bancario extiende su comprensión del mundo hacia los alumnos, los domestica, a diferencia del buen educador, quien "rechaza la domesticación de los hombres, su tarea corresponde al concepto de comunicación, no de extensión" (FREIRE, 2002, p. 24). A partir de los años sesenta, y con el objeto de romper la pedagogía bancaria, junto a un numeroso equipo de trabajo, Freire realizaba investigaciones de 
campo cuyo objetivo era descubrir un universo vocabular representativo de la comunidad que sería alfabetizada. La alfabetización no sería realizada por medio de saberes distantes, sino a partir de los propios conocimientos de los alumnos, de palabras que representaran importantes fenómenos existenciales de su cultura (BRANDÃO, 2005).

Brandão (1991), nos indica que esta primera etapa del método recibió distintos nombres por parte de Freire: 'levantamiento del universo vocabular' (en Educación como práctica de Libertad), 'descubierta del universo vocabular' (en Concientización) 'pesquisa del universo vocabular” (en Concientización y Alfabetización) 'investigación del universo temático' (en Pedagogía del Oprimido). No obstante, aunque de obra en obra algunas palabras cambiaban "siempre permaneció viva la misma idea: la idead de que hay un universo de habla de la cultura de la gente del lugar, que ha der ser investigado, levantado, descubierto" (1991, p. 11-12).

En síntesis, las palabras o ideas generadoras no deben ser una invención del investigador. Corresponde que sean conceptos comunes, deseablemente típicos de la cultura de las personas. Para llegar a tales palabras, Freire propone la realización de entrevistas cuyas preguntas favorezcan llegar a "deseos, frustraciones, esperanzas, deseos de participación y, frecuentemente, ciertos momentos altamente estéticos del lenguaje popular" (FREIRE, 1986, p. 73).

Cuando Freire fue Director del Departamento de Extensión Cultural de la Universidad de Recife (antes del exilio), formó un grupo de coordinadores especialistas que debían insertarse en la cultura de quienes iban a ser alfabetizados, de modo de descubrir las palabras que serían parte del proceso de alfabetización y, cuando problematizadas, de lectura del mundo ${ }^{11}$. El procedimiento de los coordinadores tenía

\footnotetext{
${ }^{11}$ Los coordinadores solían ser especialistas que realizaban todo el proceso: hacían las entrevistas, seleccionaban las palabras generadoras y luego alfabetizaban y dirigían los círculos de cultura.
} 
varias etapas: insertarse en el ambiente de los sujetos, realizar entrevistas, analizar los datos y, a partir de los hallazgos, hacer el levantamiento del universo vocabular. Después de esta acción los coordinadores agrupaban las palabras a partir de profesiones u oficios. Por ejemplo: en un grupo, las palabras típicas de los albañiles de la ciudad; en otro, aquéllas que corresponden a los campesinos y campesinas, es decir, a aquéllos que viven en áreas rurales. Producto de este trabajo, este Departamento de Extensión Cultural llegó a contar con un considerable acervo de palabras generadoras.

Como las entrevistas arrojaban una innumerable cantidad información, los coordinadores realizaban un proceso selectivoreductivo.

\section{Los criterios de elección de las palabras generadoras}

El siguiente paso de la primera etapa del MPF es la selección de las palabras generadoras. Para ello, se consideraba la significación de los vocablos para la comunidad. En la mayoría de los casos las palabras salían de frases enteras, tal como destaca Brandão, quien tuvo extraordinaria experiencia con el método:

Frases como esta: (...) 'los niños de aquí aprenden con los más viejos, viendo a la gente en el campo, en el trabajo todo el día. Los menorcitos ayudan trayendo la comida desde la casa hasta aquí. Los mayorcitos ya agarran la azada y ayudan a limpiar'. De innumerables frases así -frases que recuentan la vida del lugar y que deben recordar todas las situaciones, con todas las categorías de los sujetos- salen las palabras generadores (BRANDÃO, 1991, p. 14).

Generalmente, eran elegidos entre quince y dieciocho vocablos. El propio Freire apuntaba que no era necesario un gran número para la comprensión de los fonemas básicos de la lengua portuguesa (FREIRE, 1989). Sin embargo, para seleccionar las palabras sí existían tres criterios (FREIRE, 1986, p. 74; BRANDÃO, 1991, p. 31):

a) Riqueza fonética: que permitan tratar diversas habilidades fonéticas. 
b) Dificultad progresiva: que las palabras posibiliten componer otros conceptos más difíciles.

c) Dimensión pragmática: que los vocablos estén cargados de simbolismos sociales, culturales y políticos que recorren o afectan la vida de las personas que los hablan.

Es justo señalar que los dos primeros criterios pueden ser observados en los métodos tradicionales de alfabetización, pero el tercero era nuevo y revolucionario, es decir, constituía una invención de Freire. En definitiva, las palabras seleccionadas debían responder a dos aspectos fundamentales: permitir una progresiva dificultad en la alfabetización y favorecer la discusión sobre problemas que afecten directa e indirectamente la vida de los alfabetizandos.

a) Etapa 2: los círculos de cultura y la toma de conciencia crítica

Los círculos de cultura tenían inicio una vez elegidas las palabras generadoras. Se llaman círculos porque «todos están envueltos en un equipo de trabajo en que todos enseñan y aprenden». Se llaman 'de cultura' porque el círculo produce modos propios, nuevos, solidarios y colectivos de pensar. Los participantes, motivados por la curiosidad de aprender, van entendiendo aquéllo que construyen a partir del lenguaje, ejercicio que según Freire los convierte en seres de historia (FREIRE, 1986). Piensa Freire que el lenguaje

(...) también es cultura. Ella es la fuerza mediadora del conocimiento; pero también es, ella misma, conocimiento. Creo que todo eso pasa también a través de las clases sociales. Una pedagogía crítica propone esa comprensión cultural dinámica y contradictoria, y la naturaleza dinámica y contradictoria de la educación como un objeto permanente de curiosidad por parte de los educandos (FREIRE \& MACEDO, 2006, p. 33)

En fin, los vocablos seleccionados eran presentados a los estudiantes, quienes junto al animador del grupo eran retados a 
comprender las situaciones codificadas. Dicho de otro modo, los alfabetizandos eran desafiados a dialogar en torno a situaciones que aparecían como enigmáticas, y a superar, por lo tanto, sus limitaciones de lectura del mundo por medio de un análisis crítico de la realidad. En consonancia con la concepción teórica y filosófica de Freire, eran discutidos los conceptos antropológicos de cultura, de historia y de ser humano. Se esperaba que este proceso permitiera la concienciación de cada uno de los involucrados acerca de su papel como un sujeto cultural e histórico, capaz de intervenir y transformar la naturaleza por medio de su trabajo.

El proceso de codificación/decodificación, y por sobre todo de concientización, era llevado a cabo primeramente a partir de dos dinámicas, las 'fichas de cultura' y la 'lectura de la palabra'. Luego de adquirido cierto nivel de lecto-escritura se utilizaban textos breves, contenidos en los llamados 'cadernos de pós-alfabetização'.

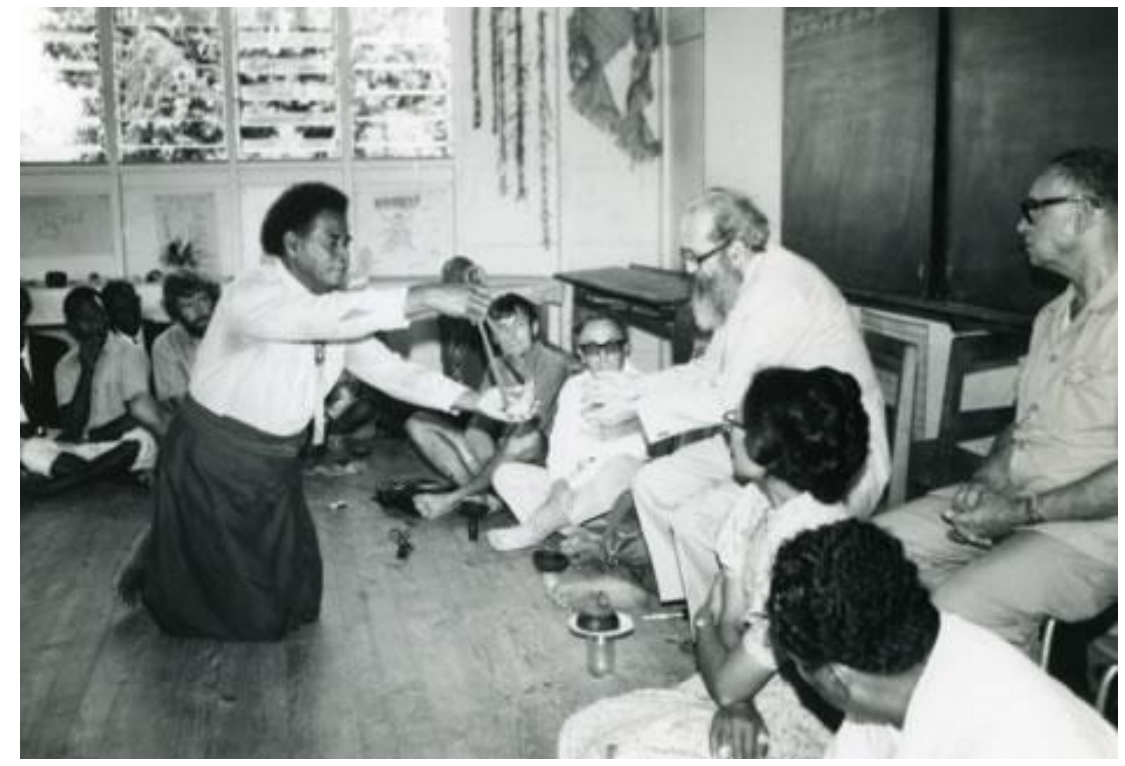

Imagen 1: Paulo Freire promoviendo la alfabetización en las Islas Fiyi.

Fuente: Projeto Memória. 
a) Las fichas de cultura

Las fichas de cultura son imágenes que representan experiencias existenciales vividas por el grupo. Luego de la observación y de la lectura, las fichas generan los primeros intercambios de ideas y discusiones entre los estudiantes y entre los alumnos y el animador. Señala Brandão las fichas de cultura

introducen ideas de base que, partiendo de situaciones existenciales, posibilitan la aprehensión colectiva del concepto 'cultura' y conducen a otros conceptos fundamentales que muchas veces reaparecerán y serán rediscutidos durante todo el trabajo de alfabetización: 'trabajo', 'diálogo', 'mundo', 'naturaleza', 'hombre', 'sociedad' (BRANDÃO: 1991, p. 21)

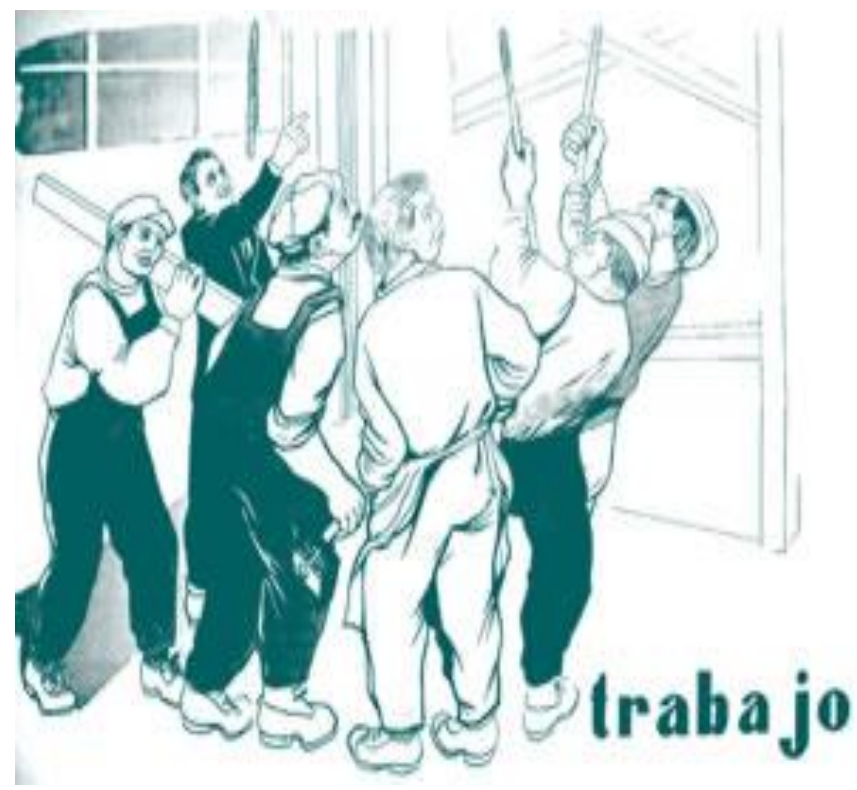

Imagen 2: Ficha de cultura utilizada en Chile.

Fuente: Instituto Paulo Freire. 
En Educación como Práctica de Libertad (1989), Freire presenta varios ejemplos de fichas de cultura aplicadas a grupos de alumnos. En una de estas imágenes, aparece un indígena con un arco y una flecha, cazando a un pájaro. Frente a esa ficha, los educandos eran cuestionados sobre el hecho si las plumas del pájaro, que eran utilizadas para construir coronas, eran o no un elemento cultural. Las reflexiones llevaban a la comprensión de que las plumas en el pájaro pertenecen al mundo natural, sin embargo, cuando el indígena las obtiene y luego las transforma con su trabajo pasan a pertenecer al mundo cultural (FREIRE, 1989, p. 128).

En muchas obras Freire narra sus experiencias y aprendizajes en la aplicación del método a partir de imágenes. En esa Esa escuela llamada vida (1986), Freire presenta una reflexión acerca de cómo a partir de las discusiones sobre la palabra generadora los educandos tomaban conciencia de que eran agentes transformadores del mundo y productores de cultura (FREIRE \& BETTO, 1986).

Preguntas como estas animaban el diálogo en los círculos de cultura ¿Cuándo termina el ser humano de cultivarse? ¿Cuándo para de adquirir sistemáticamente conocimientos? ¿Necesitamos cultivarnos en el área política? ¿Y en el área religiosa? ¿Y en el área artística?; Nosotros, ¿participamos en los desafíos del mundo, de nuestro país, de nuestro grupo? ¿Nos afectan los problemas que sufre la humanidad? A través de estos cuestionamientos, Freire observa lo que puede hacer 'la fuerza creadora del diálogo'. Estas preguntas favorecen reflexionar acerca de la posición que tenemos en el mundo, sobre el mundo, sobre el poder que poseemos para transformarlo. En efecto, Freire trata de situar al sujeto en un contexto histórico, que interprete cuál es su rol dentro de la realidad que le pertenece. A este fenómeno Freire lo llamó 'fuerza transformadora'.

b) Lectura del mundo y la lectura de la palabra 
Mucho se ha divulgado que el método de Freire conseguía alfabetizar a los estudiantes entre uno o dos meses, y que su efecto en el desarrollo social de las personas era altamente significativo ${ }^{12}$. Por razones de espacio, aquí no nos preocuparemos de esto, sino del procedimiento. Como ejemplo, citamos la palabra BENEDITO, un nombre de cuño religioso bastante común de las zonas camperas de Brasil. Este concepto fue seleccionado como una palabra generadora en una de las experiencias del MPF. La lectura de la palabra era hecha varias veces. Luego, este mismo vocablo era presentado con sus sílabas separadas, BE - NE - DI - TO y, posteriormente, cada una de las sílabas eran exhibidas con sus familias silábicas:

\begin{tabular}{|l|l|}
\hline BE & Ba - be - bi - bo - bu \\
\hline NE & Na - ne - ni - no - nu \\
\hline DI & Da - de - di - do - du \\
\hline TO & Ta - te - ti - to - tu \\
\hline
\end{tabular}

Después de varias lecturas, se animaba a los educandos a formar otras palabras utilizando las nuevas silabas. Algunos ejemplos de palabras formadas por los educandos que participaban del Círculo de Cultura citado por Brandão (1991, p. 21) fueron: botina, banana, dedo.

\footnotetext{
${ }^{12}$ En el siguiente link es posible encontrar algunos relatos del primer grupo de estudiantes que fueron alfabetizados con el MPF. Vale el tiempo leerlos para reflexionar: http://g1.globo.com/rn/rio-grande-do-norte/noticia/2013/04/1-turma-do-metodo-paulofreire-se-emociona-ao-lembrar-das-aulas.html (consulta: 12/01/2018)
} 


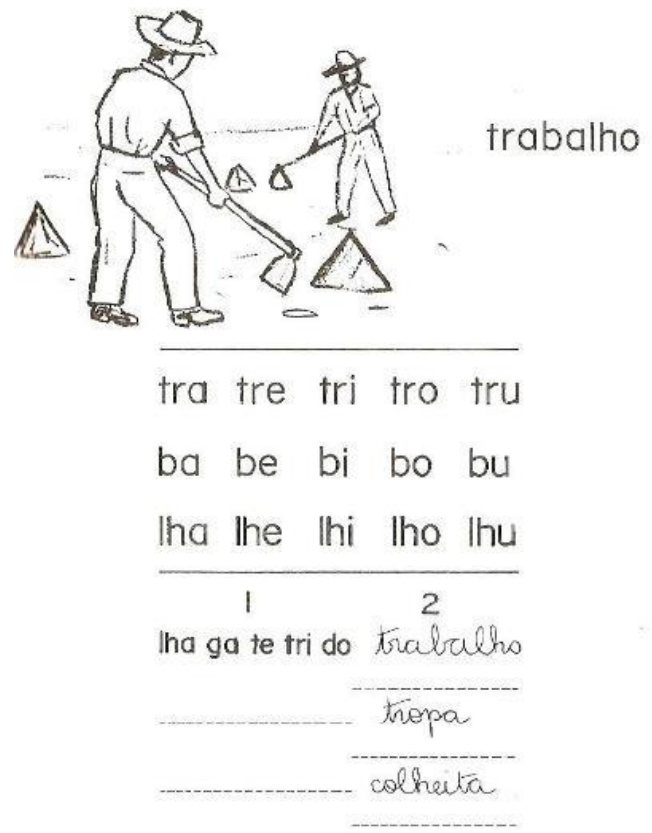

Imagen 3: Parte del Cuaderno de alfabetización.

Fuente: Instituto Paulo Freire.

a) Lectura de un texto

La lectura de textos está incluida en los llamados Cuadernos de ejercicios de posalfabetización. El objetivo es que los alumnos construyan saberes a partir de las ideas centrales del texto. Esta actividad permite que los participantes asocien vitalmente la lectura con sus propias realidades y significados de mundo, y favorece que estas realidades sean expuestas y discutidas con los demás de modo que 'todos aprendan de todos'. La discusión y el aprendizaje sobre las ideas que envuelven al concepto es posible gracias a un ambiente dialógico de socialización y cooperación. 
Sigue un ejemplo de una lectura del cuaderno de posalfabetización

\section{Pueblo y cultura}

Los colonialistas decían que solamente ellos tenían cultura. Decían que antes de su llegada a África nosotros no teníamos historia. Que nuestra historia comenzó con la venida de ellos. Esas afirmaciones son falsas, mentirosas. Eran afirmaciones necesarias para la práctica expoliadora que ejercían sobre nosotros. Para prolongar al máximo nuestra explotación económica, ellos necesitaban tratar de destruir nuestra identidad cultural, negando nuestra cultura, nuestra historia. Todos los pueblos tienen cultura, porque trabajan, porque transforman al mundo $\mathrm{y}$, al transformarlo, se transforman.

La danza del pueblo es cultura. La música del pueblo es cultura, como cultura es también la forma como el pueblo cultiva la tierra. Cultura es también la manera que el pueblo tiene de andar, de sonreír, de hablar, de cantar mientras trabaja. El calulu ${ }^{13}$ es cultura como la manera de hacer el calulu es cultura, como cultural es el sabor de las comidas. Cultura son los instrumentos que el pueblo tiene para producir. Cultura es la forma como el pueblo entiende y expresa su mundo y como el pueblo se entiende en sus relaciones con su mundo. Cultura es el tambor que resuena en la noche, cultura es el ritmo del tambor. Cultura es el balanceo de los cuerpos del pueblo al ritmo de los tambores (FREIRE, 2001a, p. 165-166).

Es fácil percibir que estos textos también se redactaban a partir de la cultura, problemas, sueños, frustraciones, de los sujetos que serían alfabetizados. En este caso, se trata de un texto aplicado en comunidades africanas víctimas de las consecuencias de la explotación colonialista y capitalista.

Para finalizar este apartado, no está de más recordar que las dinámicas presentadas, como sabemos, están unidas de manera transversal por el elemento más representativo del MPF: el diálogo. Pero no se trata de un diálogo cualquiera, simple y espontáneo, sino uno en donde "dialogar no es preguntar al azar, un preguntar por

\footnotetext{
${ }^{13}$ Plato hecho a base de aceite de palma dendé. Puede hacerse con gallina, pescado o pata de vaca.
} 
preguntar, un responder por responder, un contentarse con tocar la periferia, apenas, del objeto de nuestra curiosidad, o un quehacer sin programa" (FREIRE, 2001, p. 84) . Para que se genere el proceso de lectura del mundo, de construcción colectiva de saberes y de toma de conciencia de la realidad (concientización), el diálogo debe establecerse en un ambiente cognoscitivo y focalizado en un objeto cognoscible, esto es, la palabra generadora que al ser problematizada «se entrega a su desvelamiento crítico». El diálogo, para que favorezca el desvelamiento de la realidad profunda en la cual se actúa, de modo alguno debe someterse a un proceso vertical en donde el director del círculo de cultura intencionalmente conduce el encuentro con el fin de que los participantes digieran sus individuales comprensiones de la realidad. Freire manifiesta largamente en su obra ¿Comunicación o Extensión?, que jamás se debe disfrazar, haciendo uso del diálogo, una mera transmisión de conocimientos (FREIRE, 2002, p. 41-43).

\section{Conclusiones generales: fundamentación de una metodología dialógica}

Freire aboga por el diálogo como recurso pedagógico en toda su obra. Esto, porque piensa que para que la educación se vuelva humanizante, crítica y constructiva, debe ser dialógica. Sin embargo, la práctica dialógica -reconoce el propio Freire- encuentra diversos obstáculos para concretizarse. Veamos:

El diálogo es el nervio central del MPF. Es la unidad de dos o más sujetos que buscan algo en común, aunque inicialmente no lo puedan bien definir, conocer, comprender. Al unirse los sujetos, se instaura una relación intersubjetiva de simpatía. Pero este diálogo tiene sus límites y posibilidades: sólo se puede dar si por lo menos hay dos elementos que, dicho sea de paso, permiten observar algunas de las bases del socialismo cristiano presentes en la pedagogía de Freire. El amor, entendido como una necesidad humana capaz de generar 
inconmensurables actos de valentía. Un amor que favorece que las partes dialogantes se consideran ambas sujetos y no objetos, lo que no da lugar a ningún tipo de opresión. Dicho de otro modo, un amor que no es posesión, sino entrega mutua. La humildad, que por sobre todo es respeto a la verdad, que nadie posee absolutamente pues el ser humano es por definición incompleto y perfectible. Estos dos valores son aquellos que no dan espacios para que exista una posible justificación, teórica o existencial, de cualquier manifestación de la opresión. Son los valores que, realizados, vendrían a dar cuerpo al valor más importante en todo marxista: la justicia social y la igualdad.

Freire se refiere a la necesidad de concientización acerca de la relación entre opresor y oprimido. El primero es considerado aquel que 'tiene más', o sea, que tiene más poderes adquisitivos/materiales y, como tal, es visto como 'ser más'. Por el contrario, el segundo es aquel que tiene poco o ningún poder adquisitivo y por ello es visto y tratado como 'ser menos'. Señala Freire (2007, p. 60) que "para los opresores el valor máximo radica en tener más y cada vez más, a costa inclusive, del derecho de tener menos, o simplemente tener nada de los oprimidos".

Esta actitud deshumaniza a los oprimidos. Pero, como observa Freire, apoyándose del pensamiento de Fromm, también deshumaniza al opresor, pues ante la tendencia a transformar todo en 'cosa', incluso las relaciones humanas (hacer de los hombres y mujeres objetos), los opresores acaban por establecer una relación necrófila con el mundo: se deshumanizan a sí mismos. En efecto, de acuerdo a Fromm (1967, p. 41), al necrófilo le gusta poseer y controlar, la imposibilidad de controlar es vista como una amenaza. Y tal forma de actuar aniquila a la vida, al otro y al sí mismo.

A pesar de la dificultad de transformación de la deshumanización, Freire (2007, p. 41) reconoce que "solo el poder que renace de la debilidad de los oprimidos, será lo suficientemente 
fuerte para liberar a ambos". Y es en este sentido donde la práctica dialógica se hace fundamental:

En su obra más famosa, la Pedagogía del Oprimido, define tanto la teoría dialógica - sus dificultades para concretizarse y potencialidades - como también la teoría anti-dialógica, que justamente impone obstáculos al diálogo. En esta obra, Freire afirma que elementos como la colaboración, la unión, la organización y las síntesis culturales pertenecen a la teoría dialógica. Mientras que la conquista, la división, la manipulación y la invasión cultural son propias de la teoría anti-dialógica (FREIRE, 1980, 2008).

De acuerdo a Freire (1980), mediante estos elementos los opresores intentan conquistar al otro y mantenerlo bajo su dominio. La única forma de mantener dicho poderío es manteniendo al oprimido dividido, pues la unión y la colaboración entre los oprimidos amenazan el poder del opresor.

Para la liberación, Freire resalta que para que los elementos de la acción dialógica se vuelvan positivos es necesaria la confianza, la fe en la capacidad de los seres humanos de transformar el mundo, el amor a la humanidad y el pronunciamiento de la palabra, rechazando la dicotomía entre la acción y la reflexión. Esto, porque considera que el énfasis en la primera - la acción - lleva al activismo; el énfasis en la segunda, lleva al verbalismo. De este modo, Freire (2005b) propone entender la acción y la reflexión como elementos indisociables, puesto que aseguraría el alcanzar la praxis transformadora. En ese sentido, la acción dialógica requiere coherencia entre lo dicho y lo hecho, pues como afirma Freire, "es la práctica lo que valida el discurso y no lo contrario" (FREIRE, 2005b, p. 61). De nada sirve un impecable discurso sin una práctica en concordancia. Tarea de todos modos bastante difícil, ¿a qué ser humano se le hace fácil hacer coincidir las palabras con los actos, los actos con las palabras, lo deseado con lo real? 
De acuerdo a Freire, estos elementos dependen de la concientización, de la educación humanizadora. Pero, ¿cómo entonces es posible garantizarlos si el proprio Freire reconoció que la educación formal, en el seno de la escuela, especialmente con jóvenes y adultos, se hace histórica y mayoritariamente por medio de una educación bancaria?, es decir, una educación que se restringe al depósito del conocimiento del profesor hacia el alumno, visto éste como alguien que nada sabe y debido a esto debe mantenerse en una postura pasiva. Entonces, ¿no sería justamente la educación escolar la más relevante en el sentido de aportar para el proceso de liberación?

Entendemos que justo en este punto Freire ofrece una de sus mayores aportaciones a la pedagogía y, en especial, a la pedagogía latinoamericana. Esto, porque Freire coloca en la mesa el hecho que la educación formal tiene la obligación de asumir el rol de educar/concientizar sobre la necesidad de la liberación entre oprimidos y opresores, en concreto romper dicha dicotomía. Para Freire, es necesario que el docente reconozca que la educación no es neutra, y que se cuestione sobre su actuación: ¿educar para qué?, ¿por qué?, ¿a favor de qué y contra qué? Interrogantes como estos ayudarán al docente a tomar consciencia de su papel en cuanto agente transformador (FREIRE, 2005a). Se trata de una obligación con los marginalizados socialmente, de transformar la sociedad desde y con ellos.

La educación transformadora y humanizadora, al fundamentar la necesidad del dialogo para desarrollarse, implica reconocer que todos poseemos saberes, aunque adquiridos en distintos contextos. Es claro que Freire comprendía que la educación ocurre en todos los espacios, y que no se limita sólo a la educación en la escuela, puesto que "para saber es necesario apenas estar vivos, así, las personas saben" (FREIRE \& HORTON, 2005, p. 86). Freire propone una educación basada en la comunidad. Su idea de revolución, mezclada con sus creencias cristianas, lo llevó a pensar que la escuela, el mundo, es un lugar en 
donde los hombres y las mujeres deben vivir en condiciones de amor y de igualdad, esto es, un mundo donde 'vivir' no sea 'sobrevivir'.

\section{Bibliografía}

AHUMADA, M. Adaptación del método de Paulo Freire para la formación de adolescentes. Tesis de Doctorado, Universidad de Barcelona, 2015.

BRANDÃO, C. $O$ que é o método Paulo Freire? São Paulo: Brasiliense, 1991.

BRANDÃO, C. Paulo Freire, o menino que lia o mundo. Uma história de pessoas, de letras e de palavras. São Paulo: Edunesp, 2005.

FRANZI, J. Experiência e educação: contribuições de Paulo Freire para a educação de pessoas jovens e adultas. Dissertação, Universidade Federal de São Carlos, 2007.

FREIRE, A. Paulo Freire: vida e obra. São Paulo: Vila das Letras, 2006.

FREIRE, P. A África ensinando a gente. São Paulo: Paz e Terra, 2003.

FREIRE, P. À sombra desta mangueira. São Paulo: Olhos d'Água, 1995.

FREIRE, P. Cartas a Guinea Bissau: registro de uma experiência em processo. Rio de Janeiro: Paz e Terra, 1977.

FREIRE, P. Conscientização: teoria e prática da libertação. São Paulo: Cortez \& Moraes, 1980.

FREIRE, P. Educação como prática de liberdade. Rio de Janeiro: Paz e Terra, 1989.

FREIRE, P. Educação e mudança. São Paulo: Paz e Terra, 1986.

FREIRE, P. Extensão ou comunicação. São Paulo: Paz e Terra, 2002.

FREIRE, P. La importancia de leer y el proceso de liberación. México DF: Siglo XXI, 2001a. 
FREIRE, P. Pedagogia da autonomia. Saberes necessários à prática educativa. São Paulo: Paz e Terra, 2005a.

FREIRE, P. Pedagogia da Tolerância. Petrópolis, RJ: Vozes, 2005 b.

FREIRE, P. Pedagogía de la esperanza. Un reencuentro con la pedagogía del oprimido. México DF: Siglo XXI, 2007.

FREIRE, P. Pedagogía del oprimido. México DF: Siglo XXI, 2008.

FREIRE, P. Política y Educación. 5ta ed. México D.F., Siglo XXI, 2001b.

FREIRE, P.; BETTO, F. Essa escola chamada vida: depoimentos ao repórter Ricardo Kotscho. São Paulo: Ática, 1986.

FREIRE, P.; FAUNDEZ, F., Por uma pedagogia da pergunta. São Paulo: Paz e Terra, 2002.

FREIRE, P.; GUIMARÃES, S., Sobre educação: diálogos. Rio de Janeiro: Paz e Terra, 1982.

FREIRE, P.; HORTON, M., O caminho se faz caminhando: conversas sobre educação e mudança social. Petrópolis, RJ: Vozes, 2005.

FREIRE, P.; MACEDO, D., Alfabetização, leitura do mundo leitura da palavra. São Paulo: Paz e Terra, 2006.

FROMM, E., El corazón del hombre. México DF: FCE, 1967.

FROMM, E. Marx y su concepto del hombre. México DF: FCE, 1994.

LOYOLA, F.; BORGES, C. A pedagogia de Pula Freira ou quando a educação se torna um ato político. Em: GAUTHIER, C.; TARDIFF, M. A pedagogia: teoria e práticas desde a antiguidade aos nossos dias. Petrópolis, RJ: Vozes, 2014.

MARX, K. Manuscritos filosófico-económicos. En: FROMM, E. Marx y su concepto del hombre. México DF: Fondo de Cultura Económica, 1994.

REYES, J. En torno a Paulo Freire. Aspectos filosóficos de su pensamiento y aportes a la reflexión de raíz latinoamericana. Tesis, Pontificia Universidad Católica de Chile, 1995. 
SOUZA, A. (Org.). Paulo Freire: vida e obra. São Paulo: Expressão Popular, 2002.

Data de registro: $17 / 01 / 2018$

Data de aceite: $23 / 05 / 2018$ 